\title{
Evaluation of pozzolime mixtures as a sustainable binder to replace portland cement in structural concrete
}

\author{
Nahida Kadum $^{1}$, Tareq al-Attar ${ }^{2},{ }^{*}$ and Zyiad Al-Azzawi ${ }^{2}$ \\ ${ }^{1} \mathrm{MSc}$, Ministry of Youth and Sport, Baghdad, Iraq \\ ${ }^{2} \mathrm{PhD}$, University of Technology, Baghdad, Iraq
}

\begin{abstract}
This study aimed to evaluate the properties of concrete mixes produced mainly of hydrated lime and different types of Pozzolan. This mixture, which is nominated as PozzoLime, is presented as an alternative sustainable binder to replace Portland cement in concrete. The study tends to optimize the Pozzolan to lime proportions with respect to workability and strength of concrete. The investigated parameters are; water to binder ratio, aggregate to binder ratio and type of Pozzolan. The effects of these parameters on properties of the mixture in fresh and hardened states are studied. The included tests were; temperature profile, slump, fresh and ovendry density, compressive, splitting tensile and flexural strength and dynamic modulus of elasticity. Silicafume, Fly ash and Metakaolin were the used Pozzolan in this study .The temperature profile through hydration (coffee cup test) shows that all PozzoLime mixtures have significantly less environmental impacts (evolved heat) than Portland cement. The results also show that structural concrete with more than $28 \mathrm{MPa}$ compressive strength at 28 days age can be produced by a binder consisted of $1: 1$ by weight ratio of Silicafume to hydrated lime, , and with a total binder content of 333 $\mathrm{kg} / \mathrm{m}^{3}$.
\end{abstract}

\section{Introduction}

The manufacture of Portland cement is an energy and carbon intensive process and it is responsible for 5 to 8 percent of the total global carbon emissions. Pozzolana-Lime cements are one of a number of 'second generation' low-carbon cements being developed to meet the demand for concrete in construction [1].

Lime was known to the Greeks and was widely used by the Romans. The Romans also knew how to make hydraulic binder, i.e. lime-Pozzolan cement by adding materials, such as volcanic ash or powdered bricks, tiles and pottery to lime [2].

Lime could be considered as a sustainable binder due to lower production energy needs, lower $\mathrm{CO}_{2}$ emission during production and $\mathrm{CO}_{2}$ absorption by carbonation on setting [3].

\footnotetext{
* Corresponding author: 40076@uotechnology.edu.iq
} 
Pozzolans, such as: Silica fume, Fly ash, Slag which are also known as supplementary cementitious materials, are in most by-products for many industrial processes. Their applications in concrete industry are well-known and had been well investigated. The definition of Pozzolanic reaction could be summarized by that it is the chemical reaction between the finely grounded siliceous or siliceous aluminous phases in Pozzolans and $\mathrm{Ca}(\mathrm{OH})_{2}$, which is a by-product of the formation of calcium silicate hydrates CSH of Portland cements, to form compounds possessing cementitious properties [4].

For sustainability requirements, Meyer [5] listed many potential tools to face the challenges resulted from using Portland cements in concrete. Some of these relevant tools are:

1. Since the main challenges are associated with the production of Portland cement, whereas concrete itself is basically environmentally friendly, a primary goal is to use as much concrete with as little Portland cement as possible.

2. Replace as much Portland cement as possible by supplementary cementitious materials, especially those that are by-products of industrial processes. This reduces the amount of $\mathrm{CO}_{2}$ generated and the amount of embedded energy.

According to that the present study was carried out as a part of a research program to produce PozzoLime concrete as a sustainable binder. This binder will contain no Portland cements and could be used as structural concrete.

\section{Experimental work}

\subsection{Materials}

The used Pozzolanic materials throughout this study were: Silica fume (ASTM C1240-10), Fly ash and Metakaolin (ASTM C618-08). A hydrated lime conforming to the ASTM C82109 was utilized to produce the PozzoLime. In addition to that, an ordinary Portland cement (ASTM C150-11, Type I) was used for comparison. Table 1 shows the chemical composition and fineness of these used materials.

Natural sand, with fineness modulus of 2.9 and specific gravity (SSD) of 2.62, was used in mixes of this work as fine aggregate. Crushed gravel, with maximum size of $14 \mathrm{~mm}$, was used as coarse aggregate. This aggregate has a bulk density of $1565 \mathrm{~kg} / \mathrm{m}^{3}$ and specific gravity (SSD) of 2.65. Tap water was used for mixing and curing of the produced concrete mixes. Glenium 54 (BASF) was the used high-range water reducing admixture. It is free from chlorides and complies with the ASTM C494-10, Types A and F.

Table 1. Chemical composition and fineness of the used binders.

\begin{tabular}{|c|c|c|c|c|c|c|c|}
\hline No. & \multicolumn{2}{|c|}{ Property } & OPC $^{*}$ & $\mathbf{L}^{*}$ & $\mathbf{S F}^{*}$ & FA $^{*}$ & MK $^{*}$ \\
\hline \multirow{9}{*}{1} & \multirow{9}{*}{$\begin{array}{c}\text { Oxide } \\
\text { Content, } \\
\% .\end{array}$} & $\mathrm{CaO}$ & 61.50 & 86.44 & 1.21 & 0.98 & 3.00 \\
\hline & & $\mathrm{SiO}_{2}$ & 21.80 & --- & 90.64 & 65.65 & 51.35 \\
\hline & & $\mathrm{Al}_{2} \mathrm{O}_{3}$ & 6.50 & $\begin{array}{ll}-- \\
--\end{array}$ & 0.02 & 17.69 & 33.40 \\
\hline & & $\mathrm{Fe}_{2} \mathrm{O}_{3}$ & 2.20 & --- & 0.01 & 5.98 & 2.30 \\
\hline & & $\mathrm{MgO}$ & 1.40 & 2.12 & 0.01 & 0.72 & 0.17 \\
\hline & & $\mathrm{SO}_{3}$ & 2.50 & --- & 0.23 & 0.19 & 0.15 \\
\hline & & $\mathrm{Na}_{2} \mathrm{O}$ & 0.28 & --- & 0.22 & 1.35 & --- \\
\hline & & $\mathrm{K}_{2} \mathrm{O}$ & 0.51 & --- & 0.15 & 2.99 & --- \\
\hline & & LOI & 2.40 & --- & 2.86 & 3.10 & 7.80 \\
\hline 2 & \multicolumn{2}{|c|}{ Surface Area (Blaine), $\mathrm{m}^{2} / \mathrm{kg}$} & 240 & 1200 & 20000 & 773 & 1100 \\
\hline
\end{tabular}




\subsection{The investigated parameters and details of concrete mixes}

A reference mix was made with ordinary Portland cement and proportioned according to the ACI 211 Committee method, ACI 211.1-92 [6]. The minimum specified compressive strength at 28 days for this mix was $30 \mathrm{MPa}$. Another nine mixes were produced in which the Portland cement was totally replaced by different Pozzolan-Lime mixtures. In all PozzoLime mixes the ratio of Pozzolan to Lime was 1: 1 by weight. Table 2 lists the details of the all produced mixes.

The experimental part of this study was designed to investigate the influence of the following parameters on the properties of fresh and hardened concrete mixes:

1. Water to binder ratio by weight, W/B.

2. Aggregate to binder ratio by weight, $\mathrm{A} / \mathrm{B}$.

As shown in Table 2, five mixes were prepared by using Silica fume and Lime as a binder. Therefore, mixes LS1, LS2 and LS3 are made with W/B ratio of $0.5,0.55$ and 0.6 respectively but with a constant A/B ratio of 4. Meanwhile, mixes LS4, LS1 and LS5 are mixes made with $\mathrm{A} / \mathrm{B}$ ratio of 3,4 and 5 respectively and with a constant $\mathrm{W} / \mathrm{B}$ ratio of 0.5 .

With respect to Fly ash, the mixture of Fly ash-Lime has failed to set and hardened for many trials, therefore, it was decided to use a ternary system of Silica fume, Fly ash and Lime to overcome this problem. According to that, three different FA to SF ratios were adopted in preparing the mixes LSF1, LSF2, LSF3. They were 10: 40, 20: 30 and 30: 20 percent by weight respectively.

For Metakaolin-Lime mix, LMK, the W/B ratio was 0.5 by weight and the $\mathrm{A} / \mathrm{B}$ was 4 by weight.

All casted specimens were moist-cured in water till the age of testing.

Table 2. Details of investigated mixes.

\begin{tabular}{|c|c|c|c|c|c|c|c|c|c|c|c|}
\hline \multirow{2}{*}{ Mix } & \multicolumn{5}{|c|}{ Binder ${ }^{*}, \mathrm{~kg} / \mathrm{m}^{3}$} & \multirow{2}{*}{$\begin{array}{l}\text { Sand } \\
\mathrm{kg} / \mathrm{m}^{3}\end{array}$} & \multirow{2}{*}{$\begin{array}{l}\text { Gravel } \\
\mathrm{kg} / \mathrm{m}^{3}\end{array}$} & \multirow{2}{*}{$\begin{array}{l}\text { Water } \\
\mathrm{kg} / \mathrm{m}^{3}\end{array}$} & \multirow{2}{*}{$\begin{array}{c}\text { HRWR } \\
\% \text { by } \\
\text { wt. of } \\
\text { binder }\end{array}$} & \multirow{2}{*}{$\begin{array}{l}\text { W/B } \\
\text { ratio }\end{array}$} & \multirow{2}{*}{$\begin{array}{c}\mathrm{A} / \mathbf{B} \\
\text { ratio }\end{array}$} \\
\hline & OPC & $\mathbf{L}$ & SF & $\begin{array}{l}\mathbf{F} \\
\mathbf{A}\end{array}$ & MK & & & & & & \\
\hline Ref & 400 & 0 & 0 & 0 & 0 & 704 & 1056 & 200 & 0 & 0.5 & 4 \\
\hline LS1 & 0 & 200 & 200 & 0 & 0 & 640 & 960 & 200 & 2.5 & 0.5 & 4 \\
\hline LS2 & 0 & 197.5 & 197.5 & 0 & 0 & 635 & 950 & 220 & 2 & 0.5 & 4 \\
\hline LS3 & 0 & 195 & 195 & 0 & 0 & 630 & 940 & 240 & 1 & 0.6 & 4 \\
\hline LS4 & 0 & 244 & 244 & 0 & 0 & 570 & 900 & 244 & 2.5 & 0.5 & 3 \\
\hline LS5 & 0 & 166.5 & 166.5 & 0 & 0 & 680 & 1020 & 166.5 & 2.5 & 0.5 & 5 \\
\hline LSF & 0 & 200 & 160 & 40 & 0 & 640 & 960 & 198 & 2 & 0.4 & 4 \\
\hline LSF & 0 & 200 & 120 & 80 & 0 & 640 & 960 & 160 & 1.5 & 0.4 & 4 \\
\hline LSF & 0 & 200 & 80 & 120 & 0 & 640 & 960 & 160 & 1 & 0.4 & 4 \\
\hline LM & 0 & 200 & 0 & 0 & 200 & 640 & 960 & 198 & 2.5 & 0.5 & 4 \\
\hline
\end{tabular}

*: $\mathrm{OPC}=$ ordinary Portland cement; $\mathrm{L}=$ Lime; $\mathrm{SF}=$ Silica fume; $\mathrm{FA}=$ Fly ash; $\mathrm{MK}=$ Metakaolin

\subsection{Testing program}

The following tests were conducted on concrete mixes in their fresh state:

- Slump test (ASTM C143-10).

- Fresh density test (ASTM C138-10).

- Setting time of test (ASTM C191-08).

- Coffee cup test (temperature rise profile) [7].

- Compressive strength test (BS 1881:P.116- 1983). 
- Splitting tensile strength test (ASTM C496-04).

- Flexural strength test (ASTM C78-10).

- Dynamic modulus of elasticity (ASTM C597-09).

- Oven-dry density and absorption tests (ASTM C642-06).

\section{Results and discussion}

\subsection{Slump, density, and absorption}

Slump and fresh density records of OPC and PozzoLime concrete mixes were taken immediately after mixing. The results of these two tests are listed in Table 3.

All the binders that were used in producing PozzoLime have higher specific surface area than the used Portland cement in producing the reference mix. Therefore, this has necessitated the use of Glenium 54 in PozzoLime mixes to keep them workable. The slump values were inversely proportional to the increase in aggregate content due to the increase in the water requirement. Also the slump improved with the increase in the Fly ash content due to the decrease in the surface area of the binder.

PozzoLime mixes had always lower fresh and oven-dry densities than the reference mix. The reduction ranged between 4 and 11 and between 6 and 9 percent for fresh and oven-dry densities respectively. The Silica fume and Metakaolin mixes show almost identical reduction. Meanwhile, the inclusion of Fly ash in the binder system causes this reduction to be lower. This could be due to that finer particles would pack better than coarser ones. However, this could be considered as an advantageous characteristic for these mixtures with respect to their impact on the formwork structure and dead load calculations.

Table 3. Result of slump, density and absorption tests.

\begin{tabular}{|c|c|c|c|c|c|c|}
\hline Mix & $\begin{array}{c}\text { W/B } \\
\text { ratio }\end{array}$ & $\begin{array}{c}\text { A/B } \\
\text { ratio }\end{array}$ & $\begin{array}{c}\text { Slump, } \\
\mathbf{m m}\end{array}$ & $\begin{array}{c}\text { Fresh } \\
\mathbf{d e n s i t y ,} \\
\mathbf{k g} / \mathbf{m}^{\mathbf{3}}\end{array}$ & $\begin{array}{c}\text { Oven-dry } \\
\text { density at 28- } \\
\mathbf{d a y}, \mathbf{k g} / \mathbf{m}^{\mathbf{3}}\end{array}$ & $\begin{array}{c}\text { Absorption } \\
\text { at 28-day, \% }\end{array}$ \\
\hline Ref & 0.5 & 4 & 98 & 2464 & 2224 & 7.5 \\
\hline LS1 & 0.5 & 4 & 135 & 2237 & 2048 & 4.1 \\
\hline LS2 & 0.55 & 4 & 122 & 2235 & 2036 & 4.8 \\
\hline LS3 & 0.6 & 4 & 133 & 2232 & 2030 & 5.4 \\
\hline LS4 & 0.5 & 3 & 138 & 2200 & 2020 & 4.9 \\
\hline LS5 & 0.5 & 5 & 126 & 2270 & 2100 & 3.9 \\
\hline LSF1 & 0.4 & 4 & 131 & 2342 & 2035 & 8.6 \\
\hline LSF2 & 0.4 & 4 & 138 & 2350 & 2061 & 7.9 \\
\hline LSF3 & 0.4 & 4 & 135 & 2357 & 2089 & 7.1 \\
\hline LMK & 0.5 & 4 & 139 & 2272 & 2088 & 8.2 \\
\hline
\end{tabular}

\subsection{Setting time}

Table 4 shows the setting time, initial and final, for the refrence, LS1, LSF3 and LMK mixes. The results demonstrate that in general, all Pozzolime mixes exhibit longer setting time than the reference mix, this may be due to the absence of $\mathrm{C}_{3} \mathrm{~A}$ and $\mathrm{C}_{3} \mathrm{~S}$ and the stiffening is taking place only due to the reaction of $\mathrm{Ca}(\mathrm{OH})_{2}$ with Pozzolanic materials which is slow 
in nature [8]. Some of the delay could be caused by the absence of ettringite as indicated by XRD test [9].

Set retardation is an advantage during hot weather, allowing more time to place and finish the concrete especially in Iraq where there is a need for retarders in summer. However, during cold weather, pronounced retardation can occur with PozzoLime mixture, significantly delaying finishing operations. Longer setting time could cause delay in formwork dismantling. Accelerating admixtures can be used to overcome this issue.

Table 4. Setting time results.

\begin{tabular}{|c|c|c|}
\hline \multirow{2}{*}{ Mix } & \multicolumn{2}{|c|}{ Setting time, hours } \\
\cline { 2 - 3 } & Initial & Final \\
\hline Ref & 2.0 & 7.5 \\
\hline LS1 & 4.5 & 35.5 \\
\hline LSF3 & 5.0 & 37.0 \\
\hline LMK & 2.5 & 29.0 \\
\hline
\end{tabular}

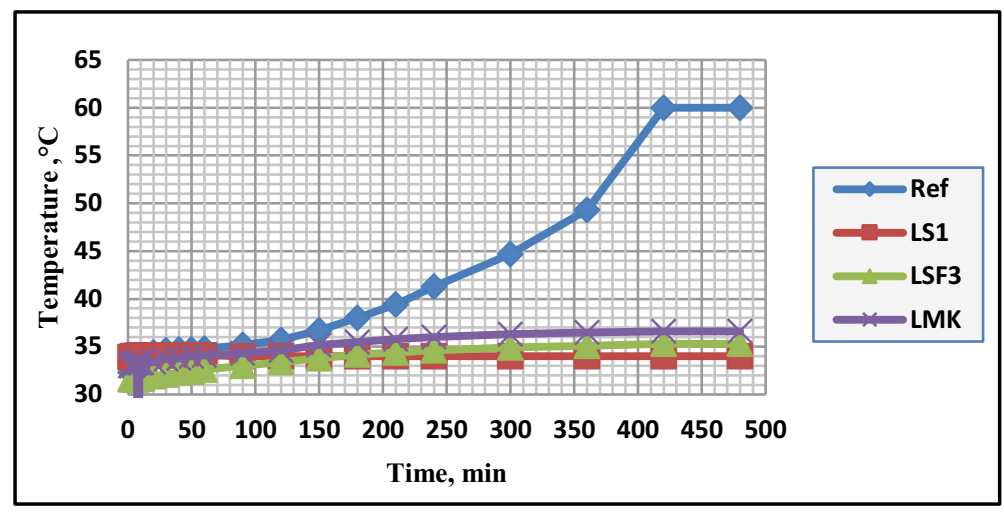

Fig. 1. Temperature rise due to hydration profile for reference, LS1, LSF3 and LMK mixes.

\subsection{Temperature rise profile due to hydration (coffee cup test)}

Cementitious paste mixtures generate heat as they hydrate. Although the coffee cup test procedur [7] is not capable of identifying specific chemical changes in the cementitious materials, it could be employed to monitor the heat generated by paste mixture materials.

This test is suitable to monitor the temperature rise due to hydration of PozzoLime paste and compare it with that generated from Portland cement hydration.

Figure 1 displays the temperature rise for pastes of four selected mixes (which could be used as an indication for the generated heat of hydration). The change in shape of the temperature profile and the difference between maximum temperatures observed for PozzoLime mixtures, as compared to Portland cement, have a lower heat of hydration than Portland cement pastes. The LS1 paste shows the lowest temperature values and seems to be constant all over the testing period. There is a continuous slight increase in temperature with time for LSF3 mixture and the LMK paste shows a higher temperature than other Pozzolans.

The observed reduction in temperature rise is beneficial in producing concrete for massive structures and hot weather [10]. 
As shown in Table 5, the results demonstrate that, in general, all mixes exhibit continuous increase in strength with the increase in curing age. It is also observed that always the reference mix has higher strength than other mixes. This could be due to the slow reaction of Lime-Pozzolana with water.

With respect to compressive strength, the Silica fume-Lime and Silica fume-Fly ashLime mixes have proved themselves suitable for producing structural concrete. All of these mixes, which were cast in cubic specimens, have attained more the $22 \mathrm{MPa}$ at 28 days age (17 MPa for cylinders). On the other hand, Metakaolin-Lime mixture could be recommended for mortar mixes and uses.

Table 5. Results of different types of strength tests for the investigated mixes.

\begin{tabular}{|c|c|c|c|c|c|c|c|c|c|}
\hline \multirow{2}{*}{ Mix } & \multirow{2}{*}{$\begin{array}{c}\text { W/B } \\
\text { ratio } \\
\text { by } \\
\text { weight }\end{array}$} & \multicolumn{3}{|c|}{$\begin{array}{c}\text { Compressive strength, } \\
\text { MPa, at age: }\end{array}$} & \multicolumn{3}{c|}{$\begin{array}{c}\text { Splitting tensile } \\
\text { strength, MPa, at age: }\end{array}$} & \multicolumn{2}{c|}{$\begin{array}{c}\text { Flexural } \\
\text { strength, MPa, } \\
\text { at age: }\end{array}$} \\
\cline { 3 - 10 } & & $\mathbf{7 ~ d}$ & $\mathbf{2 8 ~ d}$ & $\mathbf{9 0 ~ d}$ & $\mathbf{7 ~ d}$ & $\mathbf{2 8 ~ d}$ & $\mathbf{9 0}$ & $\mathbf{2 8 ~ d}$ & $\mathbf{9 0 ~ d}$ \\
\hline Ref & 0.5 & 23.1 & 35.8 & 40.1 & 1.90 & 2.50 & 3.25 & 3.1 & 4.5 \\
\hline LS1 & 0.5 & 15.6 & 27.1 & 36.6 & 1.60 & 2.20 & 2.80 & 2.3 & 3.1 \\
\hline LS2 & 0.55 & 12.8 & 23.0 & 31.1 & 1.42 & 1.90 & 2.50 & 2.0 & 2.8 \\
\hline LS3 & 0.6 & 10.2 & 18.2 & 24.4 & 1.23 & 1.60 & 2.15 & 1.8 & 2.5 \\
\hline LS4 & 0.5 & 14.9 & 26.5 & 34.9 & 1.50 & 2.10 & 2.70 & 2.2 & 2.7 \\
\hline LS5 & 0.5 & 19.4 & 28.4 & 38.6 & 1.80 & 2.35 & 3.10 & 3.4 & 3.7 \\
\hline LSF1 & 0.4 & 17.2 & 32.1 & 38.2 & 2.16 & 2.90 & 3.60 & 3.7 & 4.6 \\
\hline LSF2 & 0.4 & 15.3 & 30.4 & 36.7 & 2.10 & 2.80 & 3.30 & ---- & ---- \\
\hline LSF3 & 0.4 & 13.7 & 27.4 & 34.2 & 1.80 & 2.60 & 3.10 & ---- & ---- \\
\hline LMK & 0.5 & 5.2 & 6.1 & 7.2 & 0.41 & 0.49 & 0.66 & 0.5 & 0.6 \\
\hline
\end{tabular}

The evaluation of compressive strength gain with time is of great concern to structural engineers. ACI Committee 209 [11] recommended the following relationship for moistcured concrete made with ordinary Portland cement (ASTM C150 - Type I):

$$
\mathbf{f}_{\mathbf{c m t}}=f_{c 28} \llbracket \frac{t}{4.0+0.85 t} \rrbracket
$$

Where:

$f_{c m t}=$ mean compressive strength, MPa, at age $t$ in days.

$f_{c 28}=$ mean 28-day compressive strength, $\mathrm{MPa}$.

The PozzoLime compressive strength results have not complied with this relationship. The compressive strength values were overestimated at early age, 7 days, and underestimated in later age, 90 days. Therefore, upon the present work results, the numerical coefficients Eq. (1) may be adjusted to make the relationship fits for modeling the rate of strength gain for PozzoLime concrete, as shown in Eq. (2):

$$
\mathbf{f}_{\mathbf{c m t}}=f_{c 28} \llbracket \frac{t}{7.17+0.74 t} \rrbracket
$$

When examining the percentages of increase in the splitting tensile strength, the following remarks could be concluded:

1. Mix LS1has a similar rate of strength gain to the reference mix and this could be resulted from the high specific surface area of Silicafume, $20 \mathrm{~m}^{2} / \mathrm{g}$.

2. For the ternary system Silica fume-Fly ash- Lime, the percentages of strength increase in the interval $7-28$ days were higher than those in the interval $28-90$ days. The main variable for mixes LSF1, LSF2 and LSF3 was the Fly ash content as a replacement for the Silica fume. Fly ash is known for its slow hydration process [12]. 
3. The LSF mixes showed higher tensile strength than that of the others, even higher than the reference mix, and that may be resulted from adopting lower W/B ratio in producing them.

\subsection{Dynamic modulus of elasticity, $E_{d}$}

Based on the measurement of the ultrasonic pulse velocity, the dynamic modulus of elasticity was calculated [4]. Table 6 lists the calculated values.

The $E_{d}$ for reference mix was always higher than those for other mixes. LMK mix showed the lowest value. It could be concluded that the same trend for $E_{d}$ was observed in development as the compressive strength but with slower rates for different mixes.

Table 6. Calculated values of dynamic modulus of elasticity for the investigated mixes.

\begin{tabular}{|c|c|c|c|}
\hline \multirow{2}{*}{ Mix } & \multicolumn{3}{|c|}{ Dynamic modulus of elasticity, GPa, at age: } \\
\cline { 2 - 4 } & $\mathbf{7 ~ d a y s}$ & $\mathbf{2 8}$ days & 90 days \\
\hline Ref & 57.0 & 65.7 & 67.9 \\
\hline LS1 & 37.0 & 42.8 & 44.3 \\
\hline LS2 & 35.2 & 41.2 & 42.8 \\
\hline LS3 & 33.0 & 38.2 & 42.1 \\
\hline LS4 & 34.3 & 44.7 & 46.9 \\
\hline LS5 & 46.0 & 47.6 & 52.2 \\
\hline LSF1 & 33.9 & 34.0 & 44.4 \\
\hline LSF2 & 34.8 & 34.9 & 45.2 \\
\hline LSF3 & 35.9 & 36.1 & 46.0 \\
\hline LMK & 33.5 & 33.6 & 33.7 \\
\hline
\end{tabular}

\subsection{Effect of W/B ratio on strength development of PozzoLime concrete}

For mixes LS1, LS2 and LS3, Figures $2 \mathrm{a}$ and $2 \mathrm{~b}$ illustrate the relationships between the water to binder, $\mathrm{W} / \mathrm{B}$, ratio and compressive and splitting tensile strength respectively at a given moist-curing age. It is clear that the strength decreases with the increase of W/B ratio. And it could be outlined here that, within the investigated range of W/B ratios, strength of Pozzolime concrete, just like the Portland cement concrete, is a function of the $\mathrm{W} / \mathrm{B}$ ratio and the degree of hydration. At a given temperature of hydration, the degree of hydration is time dependent and so is the strength. Within the investigated range of W/B ratios, Abram's rule is applicable and the W/B ratio is inversely proportional to Pozzolime concrete strength. This behavior can easily be explained as the natural consequence of a progressive weakening of the matrix caused by increasing porosity with the increase in W/B ratio [13]. To generalize this conclusion, more research is needed to investigate values of $\mathrm{W} / \mathrm{B}$ ratio outside the present range. 


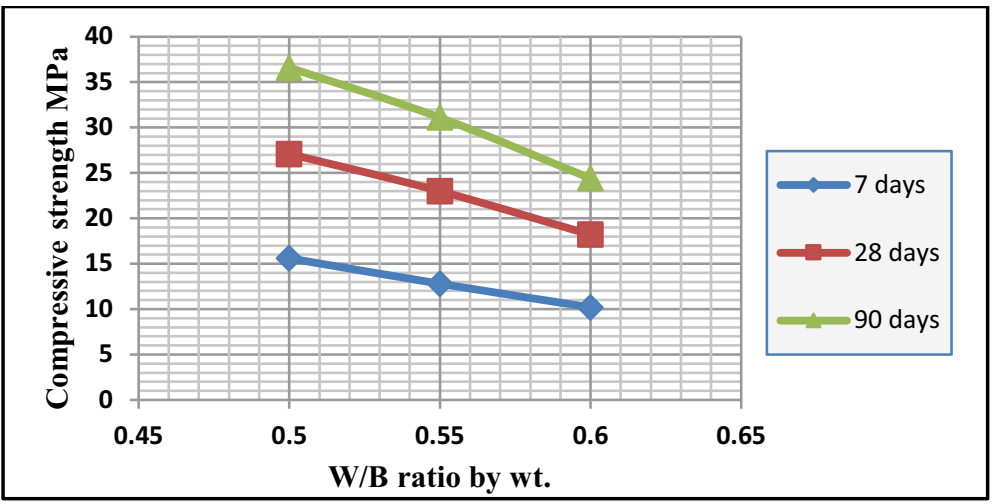

(a)

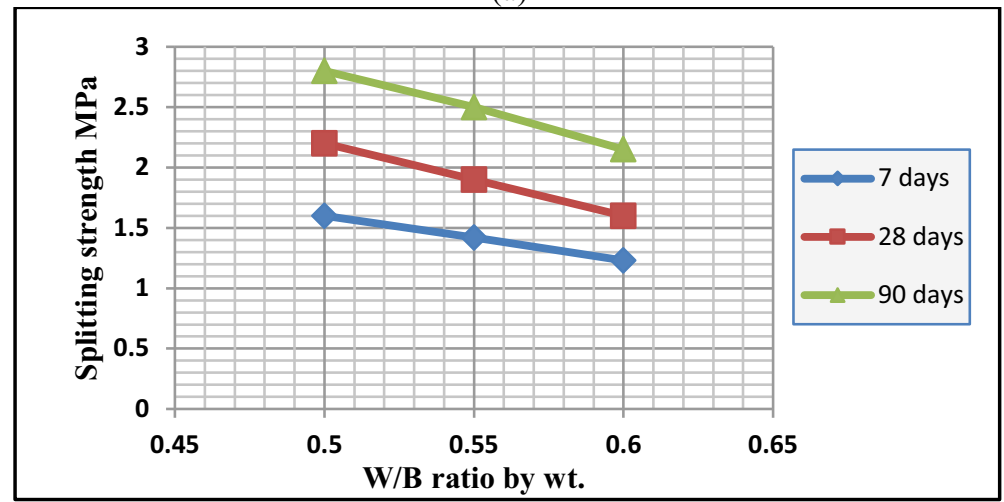

(b)

Fig. 2. Effect of W/B ratio on strength development of LS1, LS2 and LS3 mixes; a: compressive strength, b: splitting tensile strength.

\subsection{Effect of $A / B$ ratio on strength development of PozzoLime concrete}

For mixes LS1, LS4 and LS5, Figures 3.a and 3.b illustrate the relationship between aggregate to binder, $\mathrm{A} / \mathrm{B}$, ratio and strength at a given moist-curing age. These Figures show that strength increases with the increase of $\mathrm{A} / \mathrm{B}$ ratio at the same age, higher aggregate content gives higher strength. The main explanation of this influence lies in the total volume of voids in the concrete. Clearly, if the paste represents a smaller proportion of the volume of concrete, then the total porosity of the concrete is lower, and hence its strength is higher [14]. It could be observed also that curves in Figure 3 have low rate of increase (small slope) at different ages, and this could mean that aggregate content has a slight effect on strength development. 


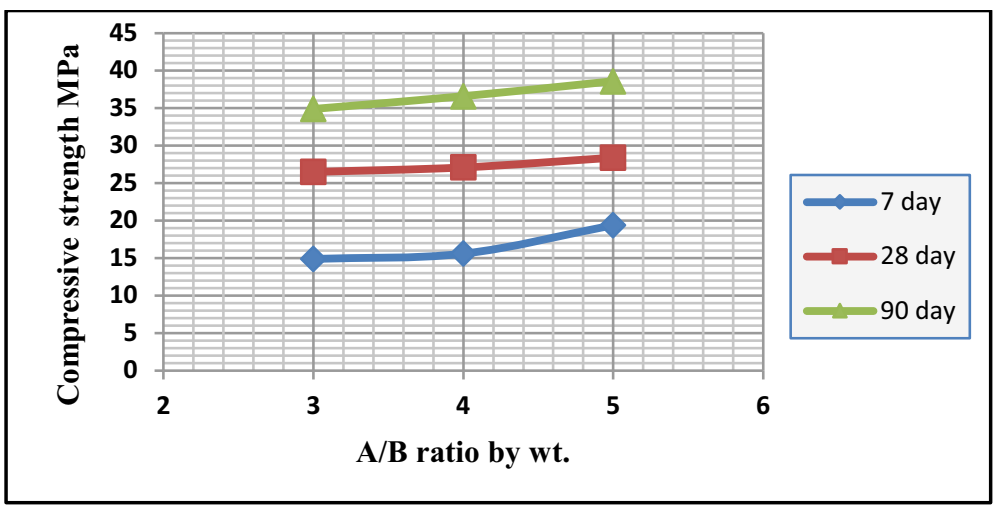

(a)

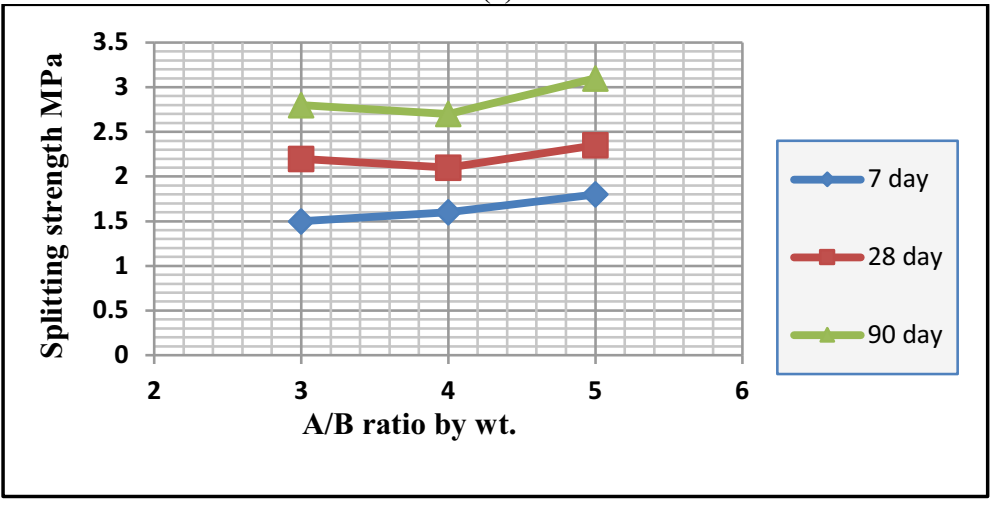

(b)

Fig. 3. Effect of A/B ratio on strength development of LS1, LS4 and LS5 mixes; a: compressive strength, $\mathbf{b}$ : splitting tensile strength.

\section{Conclusion}

According to the present experimental results, the following conclusions could be extracted:

1. The Silica fume-Lime and Silica fume-Fly ash-Lime mixes have proved themselves suitable for producing structural concrete. All of these mixes have attained more the $22 \mathrm{MPa}$ at 28 days age. On the other hand, Metakaolin-Lime mixture could be recommended for mortar mixes and uses.

2. PozzoLime mixes have always lower fresh and oven-dry densities than Portland cement mix. This could be considered as an advantageous characteristic for these mixtures with respect to their impact on the formwork structure and dead load calculations.

3. PozzoLime mixes exhibit longer setting time than the Portland cement mix. Set retardation is an advantage during hot weather but needs attention in cold regions and causes delay in formwork dismantling.

4. PozzoLime pastes, as compared to Portland cement, have a lower heat of hydration than Portland cement pastes. The Silica fume-Lime paste shows the lowest temperature rise and rate that seemed to be constant all over the testing period. There is a continuous slight increase in temperature with time for Silica fume-Fly ash-Lime paste and the MetakaolinLime paste shows a higher temperature rise than other Pozzolans. 
5. Within the investigated range of W/B ratios, Abram's rule is applicable and the W/B ratio is inversely proportional to PozzoLime concrete strength. To generalize this conclusion, more research is needed to investigate values of $\mathrm{W} / \mathrm{B}$ ratio outside the present range.

6. Different types of PozzoLime concrete strength have increased with the increase of $\mathrm{A} / \mathrm{B}$ ratio at the same age but the increase in aggregate content has a slight effect on strength development.

\section{References}

1. E. R., Grist, K. A., Paine, A., Heath, J., Norman, H., Pinder, Clea. Prod. 93, 26 (2015)

2. O., Kirca, Structural Analysis of Historical Constructions (2005)

3. A., Velosa, R., Veiga, Sust. Const., Mat. \& Prac. 775 (2007)

4. A. M., Neville, Properties of Concrete (2011)

5. C., Meyer, ASEM13, Korea, 79 (2013)

6. ACI 211.1-92, ACI Man. Conc. Prac. (2010)

7. NCPT Center, Coffee Cup Test, Iowa State University (2008)

8. V. Indrawati, A., Manaf, J Phys. Sci., 19, 51 (2008)

9. N. M. Kadum, MSc Thesis, University of Technology, Iraq (2016)

10. M. A., Caldarone, K. A., Gruber, R. G., Burg, J ACI, 91, 37 (1994)

11. ACI 209R-92, ACI Man. Conc. Prac. (2010)

12. J., Newman, B. S., Choo, Adv. Conc. Tech.: Mat. (2003)

13. P. K., Mehta, P. J., Monteiro, Conc.: Microst. Prop. \& Mat. (2005)

14. H., Lee, V., Vimonsatit, P., Chindaprasirt, K., Boonserm, J Adv. Agri. \& Env. Eng. 1, 6 (2014) 